Volume 8. No. 9, September 2020

International Journal of Emerging Trends in Engineering Research

Available Online at http://www.warse.org/IJETER/static/pdf/file/ijeter97892020.pdf

https://doi.org/10.30534/ijeter/2020/97892020

\title{
Features of the Formation of Impurity-Defective Centers in Silicon Doped with Chromium
}

\author{
Sharifa Bekmuradovna Utamuradova ${ }^{1}$, Shakhrukh Khojakbarovich Daliev ${ }^{2}$, Yuldoshali Ruzimuradovich \\ Ravshanov $^{3}$, Kakhramon Makhmudjanovich Fayzullaev ${ }^{4}$ \\ ${ }^{1}$ Institute of Semiconductor Physics and Microelectronics at the National University of Uzbekistan, 100057, \\ Tashkent, Uzbekistan. E-mail: sh-utamuradova@yandex.ru. \\ ${ }^{2}$ Institute of Semiconductor Physics and Microelectronics at the National University of Uzbekistan, 100057, \\ Tashkent, Uzbekistan. E-mail: shakhrukhd@mail.ru. \\ ${ }^{3}$ Institute of Semiconductor Physics and Microelectronics at the National University of Uzbekistan, 100057, \\ Tashkent, Uzbekistan. \\ ${ }^{4}$ Institute of Semiconductor Physics and Microelectronics at the National University of Uzbekistan, 100057, \\ Tashkent, Uzbekistan. E-mail: qahramon_fayz@mail.ru
}

\begin{abstract}
In this work, the processes of the formation of impurity-defect centers in silicon doped with chromium are investigated. It was found that the diffusion introduction of $\mathrm{Cr}$ impurity into $\mathrm{n}$-Si leads to the formation of three deep levels with fixed

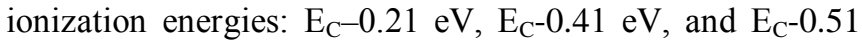
$\mathrm{eV}$, and in p-Si - two levels $\mathrm{E}_{\mathrm{V}}+0.20 \mathrm{eV}, \mathrm{E}_{\mathrm{V}}+0.41 \mathrm{eV}$. It is shown that only the levels $\mathrm{E}_{\mathrm{C}}-0.41 \mathrm{eV}$ and $\mathrm{E}_{\mathrm{C}}-0.51 \mathrm{eV}$, $\mathrm{E}_{\mathrm{V}}+0.20 \mathrm{eV}$ are associated with chromium atoms in silicon. It was found that the $\mathrm{Cr}$ atoms introduced into $\mathrm{Si}$ during its growth are electrically neutral. It is shown that high-temperature treatment (HTT) in the range $1000 \div 1200^{\circ} \mathrm{C}$ of $\mathrm{n}-\mathrm{Si}<\mathrm{Cr}>$ samples leads to activation of $\mathrm{Cr}$ atoms.
\end{abstract}

Key words : Alloying, chromium, deep level, formation efficiency, impurity, impurity-defect center, silicon.

\section{INTRODUCTION}

It is known that the technological route of manufacturing practically any semiconductor device is accompanied by various cycles of low and high temperature treatments, which inevitably leads to the formation of various kinds of defects. Such treatments have a significant effect on the development of the defect structure of silicon and the formation of impurity-defect centers formed by impurities introduced in order to modify the properties of semiconductor materials (increase photosensitivity, strain sensitivity, change in resistivity, etc.) [1]-[6].

In addition, the presence of technological impurities plays an important role in the development of the defect structure of Si.
Uncontrolled impurity atoms (iron, copper, etc.) that enter the bulk of silicon during the growth process and during technological treatments create electrically active and inactive defect states in the lattice. Technological impurities in Si always interact with dopant impurity atoms. Therefore, a change in the state of these impurities in the crystal lattice during heat treatment leads to the development of a defect structure of silicon, and also determines the efficiency of the formation of various defects [7]-[9].

Among the impurities of transition elements in silicon, chromium is the least studied impurity and there is no unambiguous opinion about the deep centers created by $\mathrm{Cr}$ in $\mathrm{Si}$ and about the behavior of its atoms in the silicon lattice. Thus, according to the data of the authors of [10], deep levels (DL) of $\mathrm{E}_{\mathrm{V}}+0.21 \mathrm{eV}, \mathrm{E}_{\mathrm{V}}+0.33 \mathrm{eV}$ are associated with $\mathrm{Cr}$ atoms in $\mathrm{Si}$, the authors of [11], [12] give a different $\mathrm{DL}$ spectrum for $\mathrm{Cr}$ : $\mathrm{E}_{\mathrm{C}}-0.41 \mathrm{eV}$ and $\mathrm{E}_{\mathrm{V}}+0.21 \mathrm{eV}$. It should be noted that the capture cross sections for these DL differ from different authors by more than two orders of magnitude.

\section{MATERIALS AND METHODS}

In order to study the features of the formation of impurity-defect centers created by $\mathrm{Cr}$ atoms in silicon, we studied the properties of silicon doped both by diffusion and in the process of growing crystals from a melt using non-stationary capacitive deep-level spectroscopy (DLTS) and photocapacity (PC). Additional experiments were conducted using neutron activation analysis (NAA).

Monocrystalline silicon of $\mathrm{n}$ - and $\mathrm{p}$-type conductivity with a specific resistance $\rho_{\text {out }}=0.3 \div 40 \mathrm{Ohm} \cdot \mathrm{cm}$ was used as the initial samples. Diffusion of $\mathrm{Cr}$ atoms in both $\mathrm{n}-\mathrm{Si}$ and $\mathrm{p}-\mathrm{Si}$ was carried out from the deposited layer of metallic impurity in the temperature range $1000 \div 1200{ }^{\circ} \mathrm{C}$ for $0.5 \div 2$ hours, 
followed by cooling at different rates.

For the experiments, we also used samples of silicon doped with chromium in the process of growing crystals from the melt, with a resistivity $\rho=10 \div 100 \mathrm{Ohm} \cdot \mathrm{cm}$.

For capacitive measurements, Schottky barriers were created by depositing gold on $\mathrm{n}-\mathrm{Si}$ and antimony on $\mathrm{p}-\mathrm{Si}$ in a vacuum. Nickel was chemically deposited as an ohmic contact, and sometimes antimony or aluminum was deposited. The DLTS spectra were measured in the modes of constant capacitance [13] and constant voltage [14], and measurements of the PC spectra were carried out according to the usual methods described in [15].

\section{EXPERIMENTAL RESULTS}

Measurements of DLTS spectra showed that after diffusion introduction of $\mathrm{Cr}$ in $\mathrm{n}-\mathrm{Si}<\mathrm{Cr}>$ samples (Fig. 1) deep levels are formed with fixed ionization energies and charge carrier capture cross sections: $\mathrm{E}_{\mathrm{C}}-0.21 \mathrm{eV}, \sigma_{\mathrm{n}}=2 \cdot 10^{-15} \mathrm{~cm}^{2}$ ( peak A), $\mathrm{E}_{\mathrm{C}}-0.41 \mathrm{eV}, \sigma_{\mathrm{n}}=6 \cdot 10^{-16} \mathrm{~cm}^{2}$ (peak B) and $\mathrm{E}_{\mathrm{C}}-0.51 \mathrm{eV}$, $\sigma_{\mathrm{n}}=1 \cdot 10^{-16} \mathrm{~cm}^{2}$ (peak $\mathrm{C}$ ), and in $\mathrm{p}-\mathrm{Si}<\mathrm{Cr}>\mathrm{DL}$ are observed $\mathrm{E}_{\mathrm{V}}+0.20 \mathrm{eV}, \sigma_{\mathrm{P}}=7 \cdot 10^{-15} \mathrm{~cm}^{2}$ (peak L) and $\mathrm{E}_{\mathrm{V}}+0.41 \mathrm{eV}$, $\sigma_{\mathrm{P}}=3 \cdot 10^{-15} \mathrm{~cm}^{2}$ (peak M). In the control heat-treated samples (without $\mathrm{Cr}$ ), deep levels $\mathrm{E}_{\mathrm{C}}-0.21 \mathrm{eV}$ (peak $\mathrm{A}^{\prime}$ ) and $\mathrm{E}_{\mathrm{V}}+0.41$ $\mathrm{eV}$ (peak $\mathrm{M}^{\prime}$ ) are also observed, and their concentration in $\mathrm{Si}$ $\langle\mathrm{Cr}\rangle_{\text {diff. much lower. These results allow us to conclude that }}$ only the efficiency of formation of levels $E_{C}-0.41 \mathrm{eV}$, $\mathrm{E}_{\mathrm{C}}-0.51 \mathrm{eV}$, and $\mathrm{E}_{\mathrm{V}}+0.20 \mathrm{eV}$ depends on technological modes (diffusion temperature $T_{\text {diff }}$ and cooling rate $v_{\text {cool }}$ ) their concentrations increase with increasing $T_{\text {diff }}$ and $v_{\text {cool }}$.

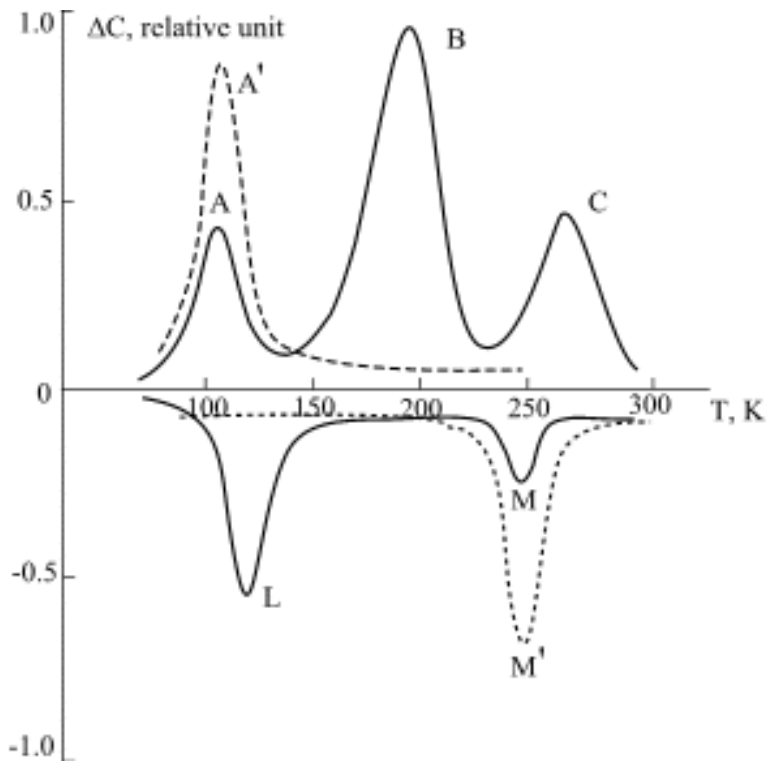

Figure 1: DLTS spectra of $\mathrm{Si}<\mathrm{Cr}>$ samples

In the samples of $\mathrm{n}$-Si diffusion doped with chromium, the photocapacity spectra were also measured, in which the relaxation of the capacitance is observed near $h v \sim 0.21 \mathrm{eV}$, hv $0.41 \mathrm{eV}$, and hv 0.51 eV (Fig. 2, curve 1). An analysis of these spectra shows that the observed relaxations are due to the charge exchange of three deep centers: $E_{C}-0.21 \mathrm{eV}$, $E_{C}-0.41 \mathrm{eV}$ and $E_{C}-0.51 \mathrm{eV}$. In the spectra of the induced PC of these samples, two steps are observed near hv $0.20 \mathrm{eV}$ and hv $0.41 \mathrm{eV}$ (Fig. 2, curve 2), caused by level exchange in the lower half of the band gap: $E_{\mathrm{V}}+0.20 \mathrm{eV}$ and $\mathrm{E}_{\mathrm{V}}+0.41 \mathrm{eV}$. Analysis of the DLTS and PC spectra shows that the thermal and optical activation energies of the detected levels in the $\mathrm{n}-\mathrm{Si}<\mathrm{Cr}>$ samples coincide within the measurement error.

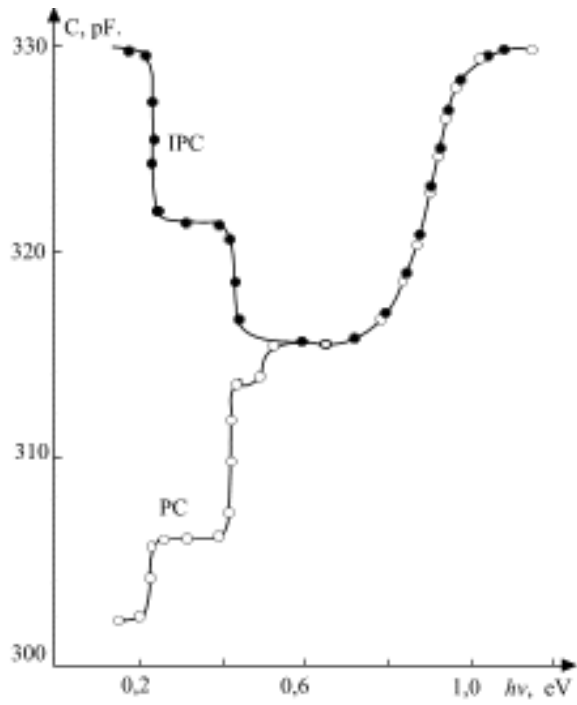

Figure 2: Spectra of PC (1) and IPC (2) of $\mathrm{Si}<\mathrm{Cr}>$ samples

Measurements of the DLTS spectra of chromium-doped silicon samples during the growth of silicon from the melt showed that no deep levels are observed in significant concentrations, although according to the NAA data the total concentration of $\mathrm{Cr}$ atoms in the bulk of silicon was about $4 \cdot 10^{15} \mathrm{~cm}^{-3}$. Hence, it can be concluded that chromium atoms introduced into silicon during the growth process do not exhibit electrical activity.

In order to test the possibility of activating chromium atoms in such samples, experiments were carried out with high-temperature treatment of $\mathrm{n}-\mathrm{Si}<\mathrm{Cr}>$ samples grown in the temperature range $\mathrm{T}=900-1200{ }^{\circ} \mathrm{C}$ followed by rapid cooling. The $\mathrm{n}-\mathrm{Si}<\mathrm{Cr}>$ plates were thoroughly washed with acid-peroxide prior to heat treatment. Annealing was carried out in quartz boats in a tube in air.

Figure 3 shows the DLTS spectrum of a silicon sample doped with chromium during growth and subjected to hightemperature treatment at $1100^{\circ} \mathrm{C}$ (curve 1) and $1200^{\circ} \mathrm{C}$ (curve 2) for 1 hour, followed by cutting quenching. 


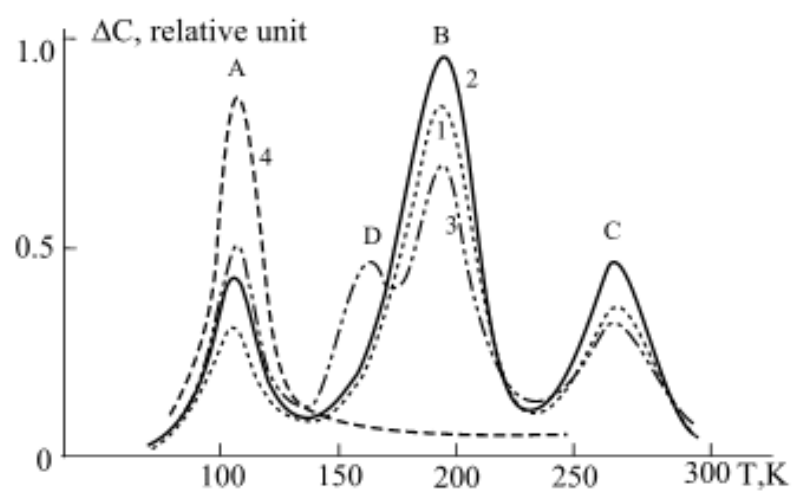

Figure 3: Typical DLTS spectra of $\mathrm{n}-\mathrm{Si}<\mathrm{Cr}>$ samples grown after heat treatment at $1100^{\circ} \mathrm{C}(1), 1200^{\circ} \mathrm{C}(2), 1200^{\circ} \mathrm{C}$ with insufficient purification (3) and control n-Si (4)

The spectra were measured in the constant voltage mode by a single scan [13]-[15]. Analysis of the measured DLTS spectra shows that high-temperature treatment of $\mathrm{n}-\mathrm{Si}<\mathrm{Cr}\rangle$ samples leads to the formation of three levels with ionization energies $\mathrm{E}_{\mathrm{C}}-0.21 \mathrm{eV}, \mathrm{E}_{\mathrm{C}^{-}}-0.41 \mathrm{eV}$, and $\mathrm{E}_{\mathrm{C}^{-}}-0.51 \mathrm{eV}$. The $\mathrm{E}_{\mathrm{C}}-0.21 \mathrm{eV}$ level is also observed in the control heat-treated samples (without $\mathrm{Cr}$ impurity); its parameters coincide with the parameters of known heat-treatment defects with the $\mathrm{E}_{\mathrm{C}}-0.21$ eV level (peak A) [16].

The deep levels $\mathrm{E}_{\mathrm{C}^{-}}-0.41 \mathrm{eV}$ and $\mathrm{E}_{\mathrm{C}}-0.51 \mathrm{eV}$ are probably due to the activation of $\mathrm{Cr}$ atoms; we observed similar levels above during diffusion doping of silicon with a chromium impurity. Note that the concentrations of the observed DLs increase with an increase in the heat treatment temperature.

An analysis of the measured DLTS spectra shows that in some samples, insufficient cleaning of the surface of $\mathrm{n}-\mathrm{Si}<\mathrm{Cr}>$ samples before high-temperature treatment leads to the appearance of a new deep center with a level of $E_{C}-0.30 \mathrm{eV}$ (peak D) in a noticeable concentration. Comparison of the DLTS spectra of such samples heat-treated in the range $900 \div$ $1200^{\circ} \mathrm{C}$ (Fig. 1, curve 3, peaks D and B) showed that the efficiency of formation of the $E_{C^{-}}-0.30 \mathrm{eV}$ level depends on the processing temperature and the degree of surface cleaning before high-temperature treatment. It was found that the appearance of this level occurs synchronously with the annealing of the $\mathrm{E}_{\mathrm{C}^{-}}-0.41 \mathrm{eV}$ level (Fig. 1, curves 2 and 3, peak B).

\section{DISCUSSION}

Measurements of DLTS spectra have shown that additional low-temperature treatment at $\mathrm{T}=100-400^{\circ} \mathrm{C}$ of $\mathrm{n}-\mathrm{Si}\langle\mathrm{Cr}\rangle$ samples that have undergone preliminary HTT at $1200^{\circ} \mathrm{C}$ leads to transformation of the energy spectrum of deep levels. As can be seen from Fig. 4 (curve 3, peak B), the concentration of the $\mathrm{E}_{\mathrm{C}}-0.30 \mathrm{eV}$ level, stimulated by high-temperature treatment, as a result of low-temperature treatment at $250^{\circ} \mathrm{C}$ for 1 hour, noticeably decreases and with a further increase in the duration of treatment, it is completely annealed.

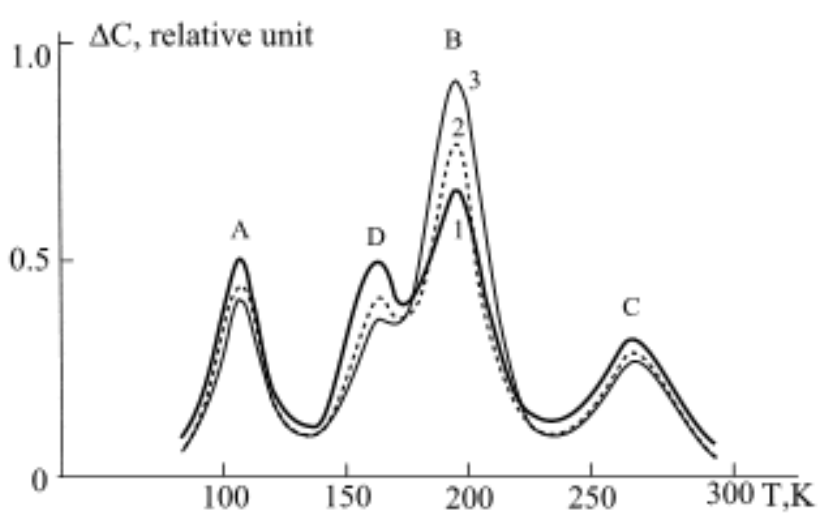

Figure 4: Typical DLTS spectra of n-Si samples doped with chromium during growth after heat treatment at $1200^{\circ} \mathrm{C}(1)$, after additional heat treatment at $250^{\circ} \mathrm{C}, 1 \mathrm{~h}$. (2) and $250^{\circ} \mathrm{C}, 2 \mathrm{~h}$. (3) Analysis of the DLTS spectra showed that annealing of the $\mathrm{E}_{\mathrm{C}}-0.30 \mathrm{eV}$ level is accompanied by an increase in the concentration of $\mathrm{E}_{\mathrm{C}}-0.41 \mathrm{eV}$ levels $\left(\Delta \mathrm{N}_{\mathrm{Ec}-0.30} \approx \Delta \mathrm{N}_{\mathrm{Ec}-0.41}\right)$.

The parameters of the $\mathrm{E}_{\mathrm{C}^{-}}-0.30 \mathrm{eV}$ level and the change in its concentration during heat treatment are similar to the behavior of the Fe-Au complex, which was reported in [17]. An additional argument in favor of identifying a center with a level of $\mathrm{E}_{\mathrm{C}}-0.30 \mathrm{eV}$ as a $\mathrm{Fe}-\mathrm{Cr}$ complex may also be the fact that the efficiency of its formation depends on the temperature and degree of purification of the samples before high-temperature treatment. It is very likely that the source of $\mathrm{Fe}$ is an insufficiently cleaned surface of $\mathrm{n}-\mathrm{Si}\langle\mathrm{Cr}\rangle$ samples before heat treatment. It is also possible that Fe atoms got into silicon during the growth process and, upon subsequent slow cooling, passed into an inactive state, and high-temperature treatment at $1200{ }^{\circ} \mathrm{C}$ activated these atoms, which may be responsible for the formation of $\mathrm{DL} \mathrm{E}_{\mathrm{C}}-0.30 \mathrm{eV}$. The assumption about the connection of this DL with the $\mathrm{Fe}-\mathrm{Cr}$ impurity pair is also supported by synchronous changes in the concentration of levels Ec- $0.41 \mathrm{eV}$ : these changes are almost equal and opposite to the changes in the concentration of DL $\mathrm{E}_{\mathrm{C}^{-}}-0.30 \mathrm{eV}$.

\section{CONCLUSION}

Thus, when studying the processes of the formation of impurity-defect centers in silicon doped with chromium, it was found that the diffusion introduction of a chromium impurity into $\mathrm{n}-\mathrm{Si}$ leads to the formation of three deep levels with fixed ionization energies: $\mathrm{E}_{\mathrm{C}}-0.21 \mathrm{eV}, \mathrm{E}_{\mathrm{C}}-0.41 \mathrm{eV}$, and $\mathrm{E}_{\mathrm{C}^{-}}-0.51 \mathrm{eV}$, and in $\mathrm{p}-\mathrm{Si}$ - two levels $\mathrm{E}_{\mathrm{V}}+0.20 \mathrm{eV} \mathrm{E}_{\mathrm{V}}+0.41 \mathrm{eV}$. It was found that only the levels $\mathrm{E}_{\mathrm{C}}-0.41 \mathrm{eV}$ and $\mathrm{E}_{\mathrm{C}}-0.51 \mathrm{eV}$, $\mathrm{E}_{\mathrm{V}}+0.20 \mathrm{eV}$ are associated with chromium atoms in silicon.

It was found that chromium atoms introduced into silicon during its growth are electrically neutral. Analysis of the results obtained shows that high-temperature treatment in the range $900-1200{ }^{\circ} \mathrm{C}$ with subsequent quenching of silicon samples doped with chromium during growth leads to the 
activation of chromium atoms with the formation of deep levels $\mathrm{E}_{\mathrm{C}^{-}}-0.41 \mathrm{eV}$ and $\mathrm{E}_{\mathrm{C}^{-}}-0.51 \mathrm{eV}$. In the $\mathrm{n}-\mathrm{Si}\langle\mathrm{Cr}\rangle$ samples, a new level $\mathrm{E}_{\mathrm{C}}-0.30 \mathrm{eV}$ is also observed, which is characterized by thermal instability and its formation or annealing is accompanied by synchronous changes in the concentration of the chromium level.

\section{REFERENCES}

1. N.N.Gerasimenko. Silicon - material of nanoelectronics, Moscow, Technosphere, 2007, p.351.

2. Y. Rodionov. Technological processes in micro- and nanoelectronics, Moscow, 2019, p.352.

3. V.A. Gurtov. Solid state electronics, Moscow, Technosphere, 2005, p..406.

4. Sh. B. Utamuradova, Kh. S. Daliev, Sh. Kh. Daliev, and K. M. Fayzullaev, The influence of chromium and iron atoms on the processes of defect formation in silicon, Applied Physics, Vo. 6, 90 (2019).

5. Sh. Utamuradova, S. Nasriddinov, Sh. Ismoilov. Electrophysical Properties of Silicon doped by Nickel impurity using Diffusion method. Intermational Journal of Emerging Trends in Engineering Research (IJETER), 2020, Vol 8, No 7, pp 3513- 3518.

6. Ragavi. R, Papanasam Esakki. Profound Understanding of Various Annealing Scheme Effects on the Electrical Characteristics of Silicon Carbide based Devices. Intermational Journal of Emerging Trends in Engineering Research (IJETER), 2020, Vol 8, No 7, pp 3513- 3518.

7. K. Ravey. Defects and impurities in semiconductor silicon, M., Mir, 1984, p. 471.

8. V.I.Fistul. Physics and Materials Science of Semiconductors with Deep Levels, Moscow., 1987, p. 232.

9. V.V. Emtsev, T.V. Mashovets. Impurities and point defects in semiconductors. M., Radio and communication, 1981, p. 248.

10. L. Milnes. Impurities with deep levels in semiconductors. - M., Mir, 1977, p.547.

11. E.M. Omelyanovskiy. Transition metal impurities in semiconductors. Moscow, 1983, p.192.

12. Rohatgi A., Davis I. R., Hopkins R. H. and Mullin P.G.Mc. Sol.St. El. 1983, V. 26, P. 1039-1048.

13. D.V. Lang. Deep level transient spectroscopy A new method to characterize traps in semiconductors. Journal of Applied Physics. 1974. Vol. 45. No. 7, p. 3023-3032.

14. G.L.Miller, D.V. Lang, L.C. Kimerling. Capacitance transient spectroscopy, Ann. Rev. Mater. Sci. 1977, v. 7, p. 377-448.

15. L.S. Berman, A.A. Lebedev. Capacitive spectroscopy of deep centers in semiconductors. L., Nauka, 1981, p.170.

16. Kh. S. Daliev. Spectroscopy of Defects in Semiconductors Doped Nickel. Journal of Scientific and Engineering Research, 2017, 4 (5), p. 211-215.

17. S.D. Brotherton, P. Bradley, E.R. Weber. Electrical observation of the Au-Fe complex in silicon, - Journal of Applied Physics., 1984, v. 55, no. 4, p. 952-956. 